\title{
Performance Evaluation of Coated Carbide Tool in Machining of Stainless Steel (AISI 202) under Minimum Quantity Lubrication (MQL)
}

\author{
J. S. Dureja ${ }^{1, \#}$, Ranjit Singh', Talwinder Singh'1, Pargat Singh', Manu Dogra², and Manpreet S. Bhatti ${ }^{3}$ \\ 1 Department of Mechanical Engineering, Punjabi University Patiala, 147002, India \\ 2 Department of Mechanical Engineering, SS Giri Punjab University Regional Centre, Hoshiarpur, 146021, India \\ 3 Department of Botanical and Environmental Science, Guru Nanak Dev University, Amritsar, 143005, India \\ \# Corresponding Author / E-mail: jsdureja73@gmail.com, TEL: +91-9501017513, FAX: +91-3046333
}

KEYWORDS: Coated carbide cutting tool, Minimum quantity lubrication (MQL), Flank wear (VB), Surface roughness (Ra), Green machining

\begin{abstract}
The benefits of cutting fluids in machining are well known, but their use is accompanied by health and environment hazards. Moreover, strict environmental regulations make the manufacturers to switch over to dry turning, which is not feasible during machining of sticky material like stainless steel and Inconel etc. Therefore, the use of minimal quantities of lubricant (MQL) can be regarded as an alternative solution and a step towards green machining. In the present investigation an attempt has been made to explore the potential of MQL turning of stainless steel with coated carbide cutting tool. Turning under MQL conditions has shown superior results (in terms of flank wear and machined surface roughness) over wet and dry turning. Signal to noise $(S / N)$ ratio as per Taguchi design revealed speed and MQL as significant parameters for minimizing flank wear and surface roughness, whereas feed can be set within range. The optimum combination of parameters are cutting speed $(58 \mathrm{~m} / \mathrm{min})$, feed rate $(0.06 \mathrm{~mm} / \mathrm{rev}$.) and MQL flow rate $(100 \mathrm{~mL} / \mathrm{h})$ for flank wear and cutting speed $(23 \mathrm{~m} / \mathrm{min})$, feed rate $(0.07 \mathrm{~mm} / \mathrm{rev}$.) and $M Q L$ flow rate $(150 \mathrm{~mL} / \mathrm{h})$ for surface roughness. Taguchi optimized conditions were validated through multiple response optimization using desirability function.
\end{abstract}

Manuscript received: September 12, 2014 / Revised: January 1, 2015 / Accepted: January 9, 2015

\section{Introduction}

The machining fraternity is constantly striving to decrease its cutting costs and increase the quality of the machined parts along with reduced operator health hazards and environmental impact as the demand for cleaner technology is rapidly increasing. The dry cutting is always preferred in the field of environmental friendly manufacturing. But there are some materials, which are sticky in nature like nickel-chromium and titanium base alloys and stainless steel etc., these materials when machined dry tend to stick to tool face leading to tool failure and result in poor surface finish on machined surface. So, conventionally machining of these sticky material is carried out under flooded coolant/ wet conditions, which involves higher manufacturing cost on one hand and poses serious environmental and health hazards on the other hand. ${ }^{1,2}$

In an attempt to economize the production cost in severe turning applications without switching over to costlier Ceramic and CBN tools, researchers are exploring the improvement in wear resistance of coated carbide tools during machining of sticky materials under MQL conditions, thereby lowering the high cutting forces as encountered in dry turning and negative impacts of flooded machining. Minimum quantity lubrication refers to the use of tiny amount of non-toxic biodegradable oil sprayed to the cutting zone by compressed air (50$500 \mathrm{~mL} / \mathrm{h}$, compared to $30,000-60,000 \mathrm{~mL} /$ hour in flooded machining) minimizing the friction, temperature and cutting forces generated during machining. ${ }^{3,4}$ Temperature reduction in the cutting zone in MQL systems is achieved mainly by the cooling effect of the compressed air and partially by evaporation of the oil mist when it meets hot tool-chip work piece combination. The concept of minimum quantity lubrication, sometimes referred to as "near dry lubrication" or "micro-lubrication" was developed a decade ago as a means of addressing the issues of environmental intrusiveness and health hazards associated with the airborne cutting fluid particles to the machine operators. The minimization of cutting fluid also leads to economical benefits, industrial hygiene, reduction of air-born particles etc. However, few disadvantages make the MQL-based machining process impractical to be adopted in many industrial production settings. ${ }^{6}$ The review of 
literature has revealed that majority of work on MQL machining has carried out on various grades of hardened alloy steels: AISI-1040, AISI 1045, AISI 1060, AISI-4340, Ni-Cr alloys like Inconel 718, brass and aluminum alloy 6061 and titanium etc., ${ }^{7-16}$ and a few researchers have explored MQL machining potential of stainless steel grades. Leppert ${ }^{17}$ investigated surface layer properties of AISI 316L stainless steel when turning under dry and MQL conditions. It was observed that the application of MQL did not significantly influence cutting forces in comparison with both wet and dry machining. Dry or MQL turning at low feed rate $(0.08 \mathrm{~mm} / \mathrm{r})$ achieved a lower surface roughness (Ra) than during emulsion turning. MQL turning at low feed rates and used cutting speeds resulted in lower $\mathrm{Ra}=1.34-1.50 \mu \mathrm{m}$ compared to dry turning, $\mathrm{Ra}=1.54-1.82 \mu \mathrm{m}$ and with emulsion $\mathrm{Ra}=1.68-2.26 \mu \mathrm{m}$ and more homogeneous machined surface with fewer defects. Bruni et al. ${ }^{7}$ during investigating effect of the lubrication-cooling technique, on workpart surface finish of AISI 420B stainless steel reported that highest influence in all cooling and lubricating conditions was exerted by the feed rate. Apart from above, no information is available on turning of Stainless Steel (AISI 202) with economical coated carbide tools under MQL conditions. Therefore present work was undertaken aimed at optimization of cutting speed; feed and MQL flow rate in order to obtain achieve minimum tool wear, high quality surface finish on machined parts. Efforts have been made to compare the performance of tool under MQL conditions with those in wet and dry turning.

\section{Taguchi Robust Design}

Taguchi Orthogonal Array Robust design is a procedure designed by Dr. Genichi Taguchi to design experimental plan to identify optimum product parameters/process factor levels so that performance characteristic (response) is not affected by uncontrollable noise factors. ${ }^{18}$ Although, similar to the other design of experiments techniques, the Taguchi design only conducts the balanced (orthogonal) experimental combinations so that factor levels are weighted equally. In this method, main parameters only, which are assumed to have an impact on process results, are positioned at different rows in a designed orthogonal array; with this a completely randomized experimental plan is conducted. Taguchi converts the objective function values to signal-tonoise $(\mathrm{S} / \mathrm{N})$ ratio, which is a logarithmic function of desired output to serve as objective functions for optimization. The term 'signal' represents the desirable value (mean) for the response parameter and the term 'noise' represents the undesirable value (S.D) for the response parameter. Therefore, the $\mathrm{S} / \mathrm{N}$ ratio is the ratio of the mean to the S.D. The observed experimental data is transformed into $\mathrm{S} / \mathrm{N}$ ratio and analyzed using ANOVA and then optimal factor-level combination exhibiting highest $\mathrm{S} /$ $\mathrm{N}$ ratio is selected. This two stage optimization procedure involving $\mathrm{S} / \mathrm{N}$ ratios indeed gives the parameter level combination, where the standard deviation is minimum, while keeping the mean on target. ${ }^{18}$ In the present investigation, the quality characteristics: tool flank wear and machined surface roughness were required to be minimized, so $\mathrm{S} / \mathrm{N}$ ratio was calculated as given by Eq. (1):

$$
S / N \text { ratio }=-10 \log \left[\frac{1}{n} \sum_{i=1}^{n} \frac{1}{Y i^{2}}\right]
$$

Where, 'Yi' is the response value for $i^{\text {th }}$ trial and ' $n$ ' is the number of replications.

\section{Experimental Details}

\subsection{Work Material}

In the current investigation, work piece material was austenitic stainless steel (low nickel and high manganese): AISI 202 grade (90HRB) in the form of round bars having with axial length $150 \mathrm{~mm}$ and diameter $32 \mathrm{~mm}$. The steel investigated here is widely employed in industrial applications such as hose clamps, trailer frames, railway rolling stock etc. The chemical composition of the work piece material is: $\mathrm{C}-0.078 \%, \mathrm{Si}-0.337 \%, \mathrm{Mn}-5.81 \%$, Ni-3.68\%, $\mathrm{S}-0.29 \%, \mathrm{Cr}-18.28 \%$, Mo- $0.049 \%$.

\subsection{Cutting Tool}

In this experimental study, TiAlN coated carbide (KYOCERAPR1125) tool, with the ISO designation of TNMG160404MS was employed for turning. The properties of cutting tool material are: Hardness $=1600 \mathrm{HRB}$, Young's modulus $=15.8 \mathrm{GPa}$, Fracture toughness $=13.0 \mathrm{MPa}$, Flexure toughness $=3400 \mathrm{MPa}$ with nose radius $=0.8 \mathrm{~mm}$. The inserts were rigidly clamped on a right hand tool holder (ISO designation MTJNR/L1616K16).

\subsection{Cutting Oil}

A straight cutting oil (Trimofin-55), supplied by Hindustan Petroleum having excellent heat removal properties and superior wetability was employed as a cutting oil in all experiments. Due to medium viscosity (32-45cst @ $40^{\circ} \mathrm{C}$ ) and high flash point flash point: $160^{\circ} \mathrm{C}$ (min), this oil is specially used for heavy duty machining applications like gear hobbing, thread cutting and machining of stainless steel.

\subsection{Experimental Procedure}

The outermost layer (ø32 $\mathrm{mm}$ to $\varnothing 31 \mathrm{~mm}$ ) of the work piece was turned off first using coated carbide inserts to avert machining of the oxidized layer. Subsequently, longitudinal turning test were carried out on a conventional lathe, Make: Batliboi, India, model TURNMAX-35 with specifications: maximum power $=2.2 \mathrm{~kW}$ and maximum spindle speed $=1120$ r.p.m. Each experimental run was conducted by using a fresh cutting edge. During experimentation cutting oil was applied on tool tool edge in the form of fine mist (mixture of compressed air + cutting oil) with the help of spray gun. The flow rate cutting of oil was regulated to obtain different $\mathrm{MQL}$ regimes. Compressed air having a constant flow rate of $146.94 \mathrm{~L} / \mathrm{h}$ was used in forming the oil mist. After finding the optimized levels for machining parameters: cutting speed, feed and cutting oil flow rate under MQL conditions; experiments were also performed at these optimal cutting conditions under dry and wet (flooded coolant) conditions to compare tool performance. During experimentation the flank wear of worn-out inserts was measured using a Toolmaker's microscope (Metzer India, magnification: X30 to X150 and $5 \mu \mathrm{m}$ resolution). The surface roughness $(\mathrm{Ra})$ of the machined specimens was evaluated with a surface roughness analyzer (Mitutoyo, SurfTest-SJ-201, cut-off length $=0.8 \mathrm{~mm}$ ). 
Table 1 Taguchi experimental plan and results for (VB) and (Ra)

\begin{tabular}{|c|c|c|c|c|c|c|c|c|c|c|c|}
\hline \multirow[t]{2}{*}{$\begin{array}{l}\text { Exp. } \\
\text { No. }\end{array}$} & \multirow[t]{2}{*}{$\begin{array}{l}\text { Speed } \\
\text { (A) } \\
\mathrm{m} / \mathrm{min}\end{array}$} & \multirow{2}{*}{$\begin{array}{c}\text { Feed } \\
\text { (B) } \\
\mathrm{mm} / \mathrm{rev} .\end{array}$} & \multirow[t]{2}{*}{$\begin{array}{l}\mathrm{MQL} \\
(\mathrm{C}) \\
\mathrm{mL} / \mathrm{h} \\
\end{array}$} & \multicolumn{3}{|c|}{$\begin{array}{l}\text { Flank wear } \\
\text { (VB) } \mu \mathrm{m}\end{array}$} & \multicolumn{3}{|c|}{$\begin{array}{l}\text { Surface roughness } \\
\text { (Ra) } \mu \mathrm{m}\end{array}$} & \multirow[t]{2}{*}{$\begin{array}{l}\mathrm{S} / \mathrm{N} \text { ratio } \\
\text { (VB) }\end{array}$} & \multirow[t]{2}{*}{$\begin{array}{l}\mathrm{S} / \mathrm{N} \text { ratio } \\
\text { (Ra) }\end{array}$} \\
\hline & & & & $\mathrm{R} 1$ & $\mathrm{R} 2$ & R3 & R1 & $\mathrm{R} 2$ & R3 & & \\
\hline 1 & $1(23)$ & $1(0.05)$ & $1(50)$ & 180 & 190 & 200 & 0.69 & 0.59 & 0.73 & -45.58 & 3.45 \\
\hline 2 & $1(23)$ & $2(0.06)$ & $2(100)$ & 70 & 110 & 130 & 0.47 & 0.44 & 0.39 & -40.53 & 7.24 \\
\hline 3 & $1(23)$ & $3(0.07)$ & $3(150)$ & 190 & 200 & 210 & 0.36 & 0.52 & 0.44 & -46.03 & 7.04 \\
\hline 4 & $2(58)$ & $1(0.05)$ & $2(100)$ & 48 & 40 & 45 & 0.85 & 0.73 & 0.77 & -32.96 & 2.10 \\
\hline 5 & $2(58)$ & $2(0.06)$ & $3(150)$ & 50 & 60 & 65 & 0.81 & 0.67 & 0.65 & -35.37 & 2.93 \\
\hline 6 & $2(58)$ & $3(0.07)$ & $1(50)$ & 130 & 140 & 150 & 0.87 & 0.8 & 0.9 & -42.94 & 1.33 \\
\hline 7 & $3(92)$ & $1(0.05)$ & $3(150)$ & 100 & 70 & 90 & 0.69 & 0.59 & 0.73 & -38.85 & 2.79 \\
\hline 8 & $3(92)$ & $2(0.06)$ & $1(50)$ & 110 & 121 & 100 & 0.47 & 0.44 & 0.39 & -40.88 & 0.15 \\
\hline 9 & $3(92)$ & $3(0.07)$ & $2(100)$ & 40 & 65 & 80 & 0.36 & 0.52 & 0.44 & -36.10 & 2.00 \\
\hline
\end{tabular}

Table 2 Factor effects for (VB) and (Ra)

\begin{tabular}{ccccccc}
\hline & \multicolumn{3}{c}{ Flank wear (VB) } & \multicolumn{3}{c}{ Surface roughness (Ra) } \\
\hline Level & $\begin{array}{c}\text { Speed } \\
\text { (A) } \\
\mathrm{m} / \mathrm{min}\end{array}$ & $\begin{array}{c}\text { Feed } \\
\text { (B) } \\
\mathrm{mm} / \mathrm{rev}\end{array}$ & $\begin{array}{c}\text { MQL } \\
\text { flow rate }(\mathrm{C})\end{array}$ & $\begin{array}{c}\text { Speed } \\
\mathrm{mL} / \mathrm{h}\end{array}$ & $\begin{array}{c}\text { Feed } \\
\mathrm{mm} / \mathrm{rev}\end{array}$ & $\begin{array}{c}\mathrm{MQL} \\
\text { flow rate } \\
(\mathrm{mL} / \mathrm{h})\end{array}$ \\
\hline 1 & -44.05 & -39.13 & -43.13 & 5.91 & 2.78 & 1.64 \\
\hline 2 & -37.09 & -38.93 & -36.53 & 2.12 & 3.44 & 3.78 \\
\hline 3 & -38.61 & -41.69 & -40.08 & 1.65 & 3.46 & 4.25 \\
\hline $\begin{array}{c}\text { Range } \\
\text { Max-Min) }\end{array}$ & 6.96 & 2.76 & 3.55 & 4.26 & 0.68 & 2.61 \\
\hline Rank & 1 & 3 & 2 & 1 & 3 & 2 \\
\hline
\end{tabular}

\section{Design of Experiments}

The controlling factors with three levels each, in this investigation were: cutting speed (A), feed rate (B) and Cutting fluid flow rate (C) with objective to achieve minimum average tool flank wear (VB) and machined surface roughness (Ra). The experiments were planned as per Taguchi's L9 orthogonal array. Each experiment was replicated three times i.e. 3 trials for each experiment, therefore: 27 experiments were conducted and results for VB and Ra given in Table 1.

\section{Analysis of Results for Flank Wear (VB)}

\subsection{Factor Effects Analysis for Flank Wear (VB)}

Table 1 illustrates the experimental results for VB. The main effects can be evaluated by analyzing raw data or $\mathrm{S} / \mathrm{N}$ ratios for flank wear as indicated in Table 2. The analysis is done by averaging the raw data or $\mathrm{S} / \mathrm{N}$ ratio data at each level of all input parameters. Ranking of factors influencing the tool flank wear was achieved on the basis of absolute difference in level average $\mathrm{S} / \mathrm{N}$ ratio between maximum and minimum values corresponding to each factor. From Table 2, the ranking of factors influencing flank wear VB is: A-C-B. The level average raw data and S/ $\mathrm{N}$ ratio are also represented in graphical form called Main Effects plot: Figs. 1(a)-(c) to evaluate the optimum levels of corresponding factors to obtain desirable response i.e. to minimize VB. The level of a factor that corresponds to minimum value of level average response or maximum level average $\mathrm{S} / \mathrm{N}$ ratio is the optimum level.

Fig. 1(a) shows the main effects plot of $(\mathrm{S} / \mathrm{N})$ ratio and (VB) Vs cutting speed. The flank wear decreases with increase in speed to $58 \mathrm{~m} / \mathrm{min}$. followed by a slight increase in flank wear with increasing speed to

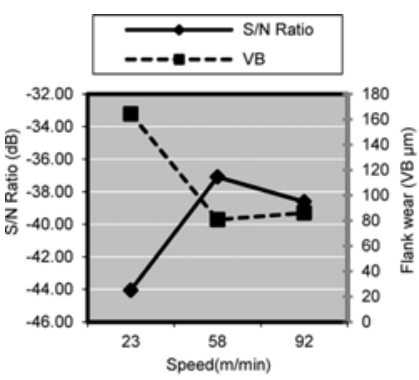

(a)

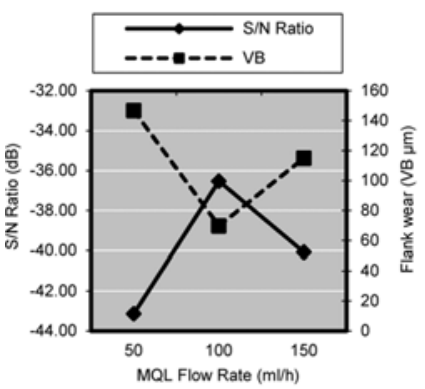

(c)

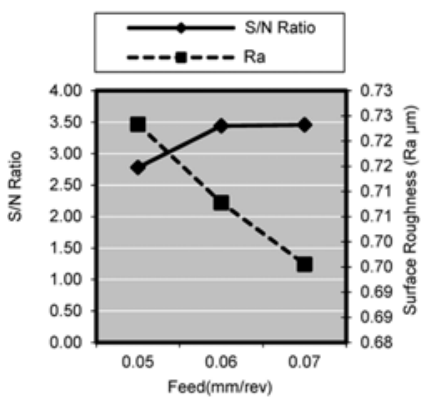

(e)

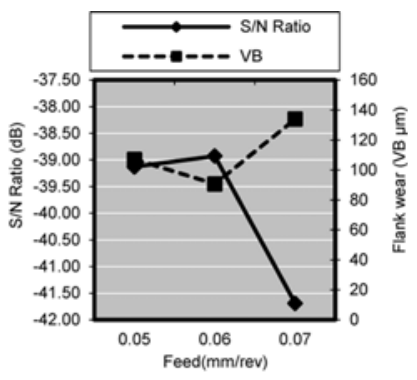

(b)



(d)

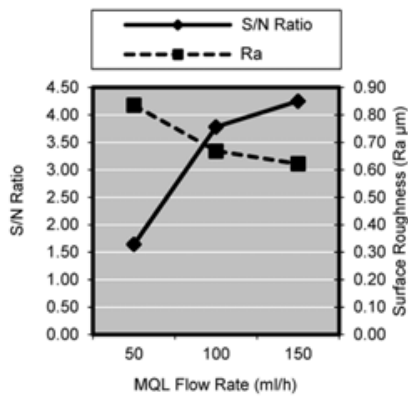

(f)
Fig. 1 Main effects for VB (a)-(c) and Ra (d)-(f)

$92 \mathrm{~m} / \mathrm{min}$. Minimum flank wear has been observed at $2^{\text {nd }}$ level of cutting speed i.e. $58 \mathrm{~m} / \mathrm{min}$. and corresponding $\mathrm{S} / \mathrm{N}$ ratio is observed to be highest, thereby indicating cutting speed $=58 \mathrm{~m} / \mathrm{min}$ to be the optimal level to minimize flank wear.

Fig. 1(b) shows the main effects plot of $(\mathrm{S} / \mathrm{N})$ ratio and (VB) Vs feed rate. Firstly, flank wear decreases with feed rate to $0.06(\mathrm{~mm} / \mathrm{rev}$.) followed by a sharp increase in flank wear with increasing feed rate to $0.07 \mathrm{~mm} / \mathrm{rev}$.

Minimum flank wear has been observed at $2^{\text {nd }}$ level of feed rate i.e. 
Table 3 ANOVA analysis of S/N ratios for (VB) and (Ra)

\begin{tabular}{|c|c|c|c|c|c|c|c|c|c|c|c|c|}
\hline & \multicolumn{6}{|c|}{ Flank wear (VB) } & \multicolumn{6}{|c|}{ Surface roughness $(\mathrm{Ra})$} \\
\hline & S.S. & D.O.F & M.S. & $\mathrm{F}$ & $\% \mathrm{C}$ & Rank & S.S. & D.O.F & M.S. & $\mathrm{F}$ & $\% \mathrm{C}$ & Rank \\
\hline Model & 145.85 & 4 & 36.46 & 7.74 & 88.56 & & 44.28 & 4 & 11.07 & 18.04 & 94.75 & \\
\hline Speed & 80.32 & 2 & 40.16 & 8.52 & 48.77 & 1 & 32.68 & 2 & 16.34 & 26.63 & 69.92 & 1 \\
\hline Feed* & $14.22 *$ & $2.00 *$ & 7.11 & 3.08 & 8.64 & 3 & 0.90 & 2 & 0.45 & 0.58 & 1.92 & 2 \\
\hline $\begin{array}{l}\text { MQL flow } \\
\text { rate }\end{array}$ & 65.53 & 2 & 32.76 & 6.95 & 39.79 & 2 & 11.60 & 2 & 5.80 & 9.46 & 24.83 & 3 \\
\hline $\begin{array}{l}\text { Pooled } \\
\text { error* }\end{array}$ & 18.85 & 4 & 4.71 & & 11.44 & & 2.45 & 4 & 0.61 & & 5.25 & \\
\hline Total & 164.7 & 8 & & & 100 & & 46.73 & 8 & & & 100 & \\
\hline
\end{tabular}

Pooled into error S.S., F $(0.05,2,4)=6.94$, speed and MQL flow rate are significant parameters

Table 4 ANOVA analysis and model of raw data for (VB)

\begin{tabular}{ccccccc}
\hline Source & S.S. & D.O.F & M.S. & F & Prob $>$ F \\
\hline Model & 74911.56 & 6 & 12485.26 & $48.76<0.0001$ & significant \\
\hline A & 39386.07 & 2 & 19693.04 & $76.91<0.0001$ & significant \\
\hline B & 8573.85 & 2 & 4286.93 & $16.74<0.0001$ & significant \\
\hline C & 26951.63 & 2 & 13475.81 & $52.63<0.0001$ & significant \\
\hline Residual & 5121.19 & 20 & 256.06 \\
\hline Lack of fit & 1001.19 & 2 & 500.59 & 2.19 & 0.1412 & $\begin{array}{c}\text { Not } \\
\text { significant }\end{array}$ \\
\hline Pure error & 4120.00 & 18 & 228.89 \\
\hline Cor. total & 80032.74 & 26 \\
\hline \multicolumn{6}{c}{ Model statistics } \\
\hline Std. dev. 16.00 & $\mathrm{R}^{2}$ & 0.9360 \\
\hline Mean & 110.52 & Adj. $\mathrm{R}^{2}$ & 0.9168 \\
\hline C.V. & \multicolumn{7}{c}{14.48} & Pred. $\mathrm{R}^{2}$ & 0.8834 \\
\hline PRESS & 9333.36 & Adeq. precision & 19.706 \\
\hline \multicolumn{7}{c}{}
\end{tabular}

$0.06 \mathrm{~mm} / \mathrm{rev}$. and corresponding highest $\mathrm{S} / \mathrm{N}$ ratio, thereby indicating feed rate $=0.06 \mathrm{~mm} / \mathrm{rev}$. to be the optimal level to minimize flank wear.

Fig. 1(c) illustrates the main effects plot between $\mathrm{S} / \mathrm{N}$ ratio and (VB) Vs MQL flow rate (C). From plot, it is clear that the flank wear initially decreases with increase in oil flow rate to $100 \mathrm{~mL} / \mathrm{h}$ followed by increase in flank wear with increasing oil flow rate to $150 \mathrm{~mL} / \mathrm{h}$. The corresponding $\mathrm{S} / \mathrm{N}$ ratio is observed highest at $100 \mathrm{~mL} / \mathrm{h}$, therefore MQL flow rate $=100 \mathrm{~mL} / \mathrm{h}$ is optimal level to achieve minimum flank wear.

\subsection{ANOVA Analysis of S/N Ratio for Flank Wear (VB)}

The analysis of variance (ANOVA) is applied to investigate statistically significant parameters influencing the quality characteristic or response parameter and to ascertain their relative contribution towards model/overall variability in response parameter. ${ }^{19}$ ANOVA is also applied to separate the total variability of the response into relative contribution of each of the controlling factor and the residual error. The ANOVA analysis was applied on $\mathrm{S} / \mathrm{N}$ data, and results are given in Table 3. The ANOVA analysis for $\mathrm{S} / \mathrm{N}$ suggested percentage contribution of input factors influencing flank wear (VB) as: Speed $=$ $48.59 \%$, MQL Flow Rate $=40.06 \%$ and feed rate $=8.53 \%$, signifying the cutting speed and MQL Flow Rate at $100 \mathrm{~mL} / \mathrm{h}$ to be the significant contributing factor influencing flank wear. Moreover, the calculated Fvalue for cutting speed (8.52) and MQL Flow Rate (6.95) is greater than $\mathrm{F}_{\text {Table }}(0.05,2,4)=6.94$, indicating cutting speed and MQL Flow Rate at $100 \mathrm{~mL} / \mathrm{h}$ as statistically significant parameters at $95 \%$ confidence interval. The ANOVA analysis has also proved that MQL flow rate at $100 \mathrm{ml} / \mathrm{h}$ contribute significantly to minimize tool wear.

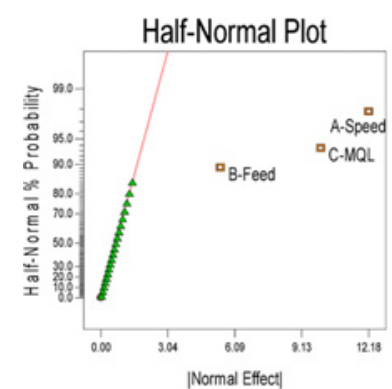

(a)

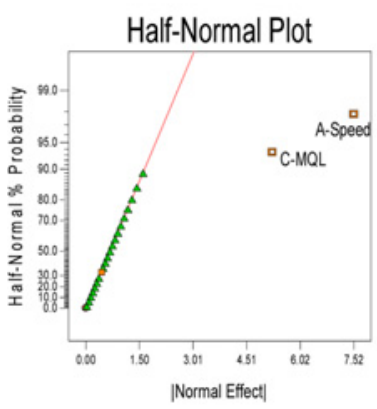

(c)

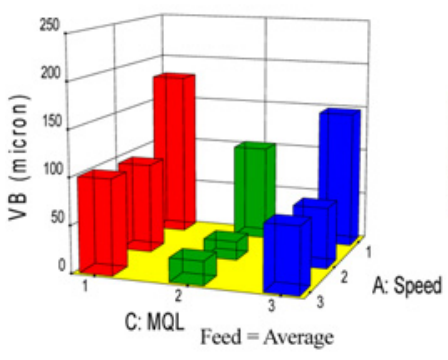

(e)

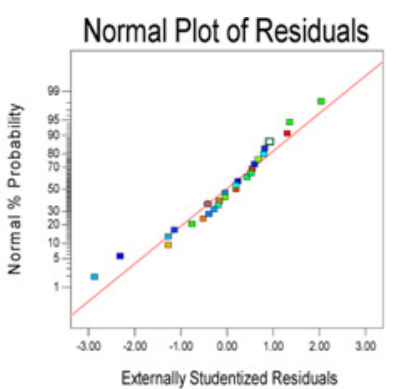

(b)

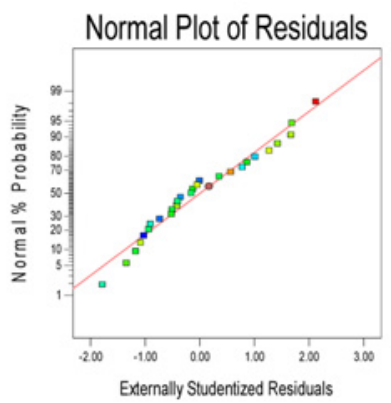

(d)

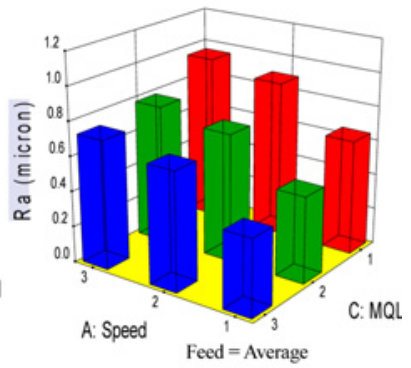

(f)
Fig. 2 Half normal probability plot and normal plot of residuals for flank wear (a)-(b) and surface roughness (c)-(d), optimal solution for VB (e), optimal solution for Ra (f)

The rank-order of the factors based on percentage contribution from ANOVA analysis is the same as that obtained earlier (based on range of level average raw data and $\mathrm{S} / \mathrm{N}$ data, Table 2) i.e. A-C-B.

\subsection{ANOVA of Raw Data (Actual Response Values) for VB}

Experimental data for all the 27 runs was examined through Taguchi Orthogonal Array (OA)-L9 $\left(3^{\wedge} 4\right)$, Table 4. Selection of significant process factors was done using Half-Normal probability plot (Fig. 2(a)). 
Table 5 ANOVA analysis and model statistics of raw data for $(\mathrm{Ra})$

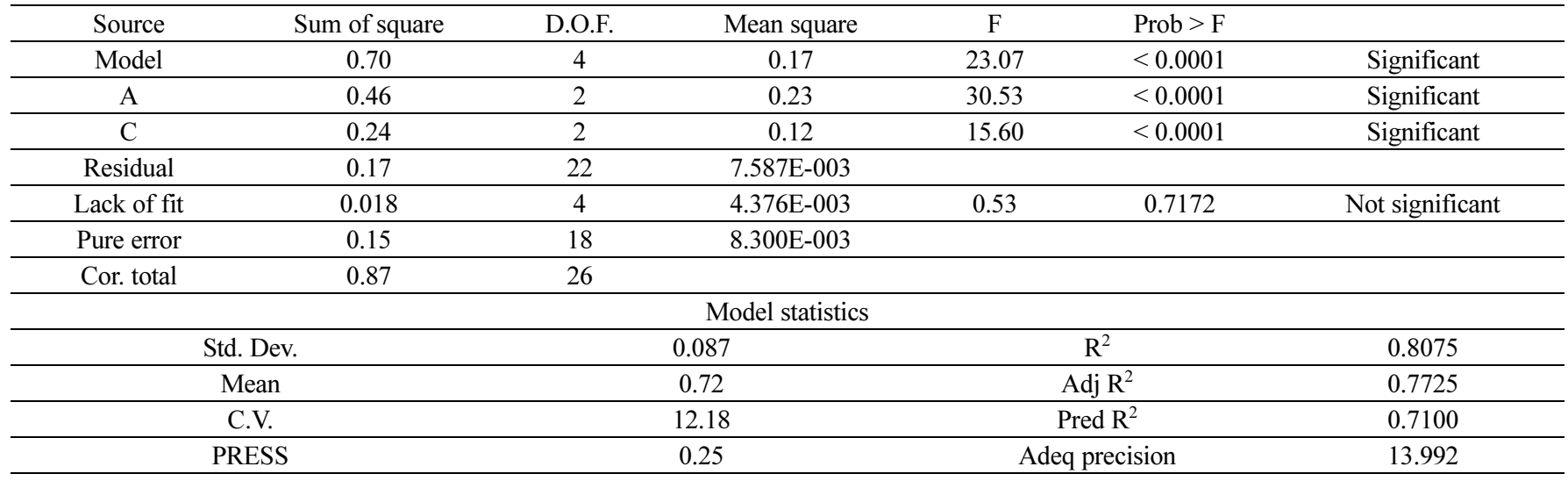

All parameters were found significant. ANOVA modelling predicted highly significant model with $99.99 \%$ significance level (Fvalue $=48.76$ and D.O.F. $=6$ ). The selected model has non-significant lack of fit $(\mathrm{p}=0.1412)$ indicated about strong signal as compared to model noise and explained $85.88 \%$ variance.

The ANOVA statistics are also given in Table 4. Fig. 2(e) illustrates 3D plot of optimal solution for VB. Minimum VB has been achieved at MQL flow rate of $100 \mathrm{~mL} / \mathrm{h}$.

\section{Analysis of Results for Surface Roughness (Ra)}

\subsection{Raw Data and S/N Ratio Analysis for Flank Wear (VB)}

Table 1 illustrates the experimental results for Ra. The main effects have been evaluated by analyzing raw data and $\mathrm{S} / \mathrm{N}$ ratios for $\mathrm{Ra}$. The analysis is done by averaging the raw data or $\mathrm{S} / \mathrm{N}$ ratio data at each level of all input parameters: Table 2. Ranking of factors on the basis of absolute difference in level average $\mathrm{S} / \mathrm{N}$ ratio for each factor influencing Ra given in Table 2 is: A-C-B. The Main Effects have been plotted: Figs. 1(d)-(f).

It is clearly indicated from Fig. 1(d) that surface roughness (Ra) increases with increase in cutting speed, where as $\mathrm{S} / \mathrm{N}$ ratio decreases with increase in cutting speed. Corresponding to minimum cutting speed $(23 \mathrm{~m} / \mathrm{min})$, best surface finish and highest $\mathrm{S} / \mathrm{N}$ ratio have been observed. Thus cutting speed $23 \mathrm{~m} / \mathrm{min}$ is the optimal level to attain minimum surface roughness (Ra).

It is clearly indicated from Fig. 1(e) that surface roughness (Ra) decreases with increase in feed rate, where as $\mathrm{S} / \mathrm{N}$ ratio increases with increase in feed rate. Corresponding to maximum feed rate $(0.07 \mathrm{~mm} /$ rev), best surface finish and highest $\mathrm{S} / \mathrm{N}$ ratio have been observed. Thus feed rate $0.07 \mathrm{~mm} / \mathrm{rev}$ is the optimal level to attain minimum surface roughness $(\mathrm{Ra})$.

It is clearly indicated from Fig. 1(f) that surface roughness (Ra) decreases with decrease in MQL flow rate, where as $\mathrm{S} / \mathrm{N}$ ratio increases with increase in MQL flow rate. Corresponding to maximum MQL flow rate $(150 \mathrm{~mL} / \mathrm{h})$, best surface finish and highest $\mathrm{S} / \mathrm{N}$ ratio have been observed. Thus MQL flow rate $150 \mathrm{~mL} / \mathrm{h}$ is the optimal level to attain minimum surface roughness $(\mathrm{Ra})$.

6.2 ANOVA Analysis of S/N Ratio for Surface Roughness (Ra) The ANOVA analysis was applied on $\mathrm{S} / \mathrm{N}$ data, and results are

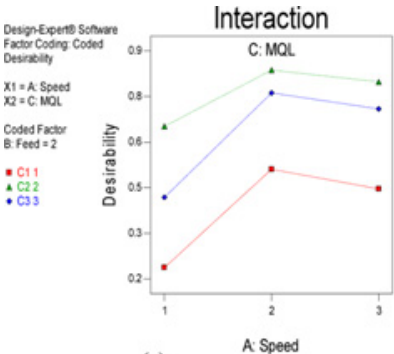

(a)

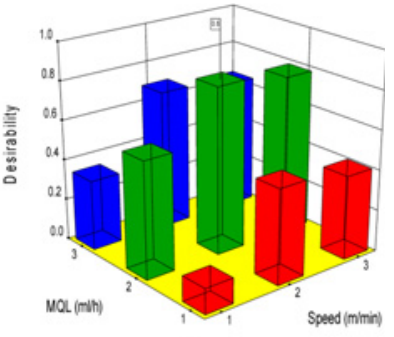

(b)
Fig. 3 (a) Two factor interaction plot between speed and MQL (b) Desirability plot showing multiple response optimization

given in Table 3. The ANOVA analysis for $\mathrm{S} / \mathrm{N}$ suggested percentage contribution of input parameters influencing surface roughness (Ra) as: Speed $=69.92 \%$, MQL flow rate $=24.83 \%$, signifying the Speed and MQL flow rate to be the significant contributing factor influencing surface roughness. The calculated F-value for cutting speed (26.63) and for MQL flow rate (9.46) is greater than $\mathrm{F}_{\text {Table }(0.05,2,4)}=6.94$, indicating Speed and MQL flow rate as statistically significant parameters at $95 \%$ confidence interval, as expected. The rank-order of the factors based on percentage contribution from ANOVA analysis is the same as that obtained earlier (based on range of level average raw data and $\mathrm{S} / \mathrm{N}$ data, Table 2) i.e. A-C-B.

\subsection{ANOVA of Raw Data (Actual Response Values) for Ra}

The ANOVA analysis and statistics of raw data for Ra are given in Table 5. Selection of significant process factors was done using HalfNormal probability plot (Fig. 2(c)). Speed and MQL flow rate were found significant. ANOVA modelling predicted highly significant model with $99.99 \%$ significance level $(\mathrm{F}$-value $=23.07$ and D.O.F. $=4)$. The selected model has non-significant lack of fit $(p=0.7172)$ indicated about strong signal as compared to model noise and explained $80.75 \%$ variance. Model residual errors passed the Normal probability test (Fig. 2(d)), thus predicted model can be used to navigate the design space. Fig. 2(f) illustrates 3D plot of optimal solution for Ra. Minimum VB has been achieved at MQL flow rate of $150 \mathrm{~mL} / \mathrm{h}$.

\subsection{Multiple Response Optimization}

Regression equations as per fitted models (Table 4 and Table 5) were simultaneously solved to propose optimal solution. The goals were set as minimizing VB (higher importance of 3 on scale of 5) and 
Table 6 Comparison of dry, wet and MQL techniques

\begin{tabular}{cccccccccc}
\hline & & & \multicolumn{4}{c}{ DRY } & \multicolumn{2}{c}{ WET } & \multicolumn{2}{c}{ MQL } \\
\hline S. & Speed & Feed & Flow & VB & Ra & VB & Ra & VB & Ra \\
No. & $\mathrm{m} / \mathrm{min}$. & $\mathrm{mm} / \mathrm{rev}$. & Rate & $\mu \mathrm{m}$ & $\mu \mathrm{m}$ & $\mu \mathrm{m}$ & $\mu \mathrm{m}$ & $\mu \mathrm{m}$ & $\mu \mathrm{m}$ \\
\hline 1 & 58 & 0.06 & 100 & 145 & 1.36 & 140 & 0.74 & 55 & 0.74 \\
\hline 2 & 23 & 0.07 & 150 & 180 & 0.83 & 150 & 0.95 & 110 & 0.5 \\
\hline
\end{tabular}

Ra (lower importance of 1 on scale of 5) to arrive at best solution. 2FI between speed and MQL indicated that MQL of $100 \mathrm{~mL} / \mathrm{h}$ has higher chances of achieving the goal (Fig. 3(a)) and 3D desirability plot at different combinations of speed and MQL is given in Fig. 3(b). Desirability function details are given elsewhere. ${ }^{20}$

\section{Comparing Performance of Tool under Dry, Wet and MQL Conditions}

After evaluating the optimized levels of input parameters under MQL turning; experiments under dry and wet conditions were performed at optimised parameter levels to compare tool performance in terms of tool flank wear and machined surface roughness with those in dry and wet turning. Results have revealed lower tool flank wear and machined surface roughness compared to dry and wet turning, Table 6, validating that MQL is a better alternative to dry and wet cutting of sticky materials like stainless steel.

\section{Validation Test}

\subsection{Flank Wear (VB)}

The predicted optimum response VB has been evaluated on the basis of two statistically significant parameters A2 and C2: Eq. (2)

$$
\text { Predicted Optimum VB }=\mu+(\overline{A 2}-\mu)+(\overline{C 2}-\mu)
$$

The predicted optimum $\mathrm{VB}=40.37 \mu \mathrm{m}$. The optimum conditions $\mathrm{A} 2$ and $\mathrm{C} 2$ are also included in Experiment No. 4, Table 1 with $\mathrm{VB}_{\text {avg. }}=44.33 \mu \mathrm{m}$. Since the least count of micrometer is 5 microns and difference of 4 microns is irrelevant. So validates the optimum result.

\subsection{Surface Roughness (Ra)}

The predicted optimum response Ra has been evaluated by two significantly parameters $\mathrm{A} 1$ and $\mathrm{C} 3$ : Eq. (3)

$$
\text { Predicted Optimum } \mathrm{Ra}=\mu+(\overline{A 1}-\mu)+(\overline{C 3}-\mu)
$$

The predicted optimum $\mathrm{Ra}=0.43 \mu \mathrm{m}$. The optimum conditions A1 and $\mathrm{C} 3$ are also included in Experiment No. 3, with Ra avg. $=0.44 \mu \mathrm{m}$, Table 1, So it validates the optimum result.

\section{Conclusions}

The present investigation was carried out to explore the potential of
MQL turning of stainless steel (AISI 202) with coated carbide cutting tool. The performance of cutting tool in terms of tool flank wear and machined surface roughness under MQL conditions has also been compared with wet and dry turning. Following conclusions are drawn from the analysis of results:

Turning under MQL conditions has shown superior results over wet and dry turning in terms of low tool wear and machined surface roughness, which validates the benefit of MQL Technique in turning application compared to Wet and Dry System as revealed by previous authors. $^{5}$

1. Taguchi optimization, $\mathrm{S} / \mathrm{N}$ ratio and ANOVA analysis revealed cutting speed as the most influencing parameter (contribution $=48.77 \%$ for $\mathrm{VB}$ and $69.92 \%$ for Ra) followed by MQL flow rate (contribution $=39.79 \%$ for $\mathrm{VB}$ and $24.83 \%$ for $\mathrm{Ra}$ ) in minimizing tool wear and surface roughness respectively.

2. The optimum combination of parameters/conditions (Taguchi optimization) to minimize tool wear is: cutting speed $=58 \mathrm{~m} /$ $\mathrm{min}$, feed rate $=0.06 \mathrm{~mm} / \mathrm{rev}$. and MQL flow rate $=100 \mathrm{~mL} / \mathrm{h}$.

3. The optimum combination of parameters /conditions (Taguchi optimization) to minimize surface roughness is: cutting speed $=23 \mathrm{~m} / \mathrm{min}$, feed rate $=0.07 \mathrm{~mm} / \mathrm{rev}$. and MQL flow rate $=150 \mathrm{~mL} / \mathrm{h}$.

4. Multiple response optimization using desirability plot predicted cutting speed $=58 \mathrm{~m} / \mathrm{min}$, feed rate $=0.06 \mathrm{~mm} / \mathrm{rev}$. and $\mathrm{MQL}$ flow rate $=100 \mathrm{~mL} / \mathrm{h}$ to achieving flank wear of $36.63 \mu \mathrm{m}$ and surface roughness of $0.74 \mu \mathrm{m}$.

5. Minimum quantity lubrication (MQL) machining is a step towards green machining by optimizing the MQL flow rate.

\section{REFERENCES}

1. Adler, D., Hii, W.-S., Michalek, D., and Sutherland, J., "Examining the Role of Cutting Fluids in Machining and Efforts to Address Associated Environmental/Health Concerns," Machining Science and Technology, Vol. 10, No. 1, pp. 23-58, 2006.

2. Davim, J. P., Sreejith, P., and Silva, J., "Turning of Brasses using Minimum Quantity of Lubricant (MQL) and Flooded Lubricant Conditions," Materials and Manufacturing Processes, Vol. 22, No. 1, pp. 45-50, 2007.

3. Thakur, D. G., Ramamoorthy, B., and Vijayaraghavan, L., "Investigation and Optimization of Lubrication Parameters in High Speed Turning of Superalloy Inconel 718," International Journal of Advanced Manufacturing Technology, Vol. 50, No. 5-8, pp. 471478, 2010.

4. Wang, C.-D., Chen, M., An, Q.-L., Wang, M., and Zhu, Y.-H., "Tool Wear Performance in Face Milling Inconel 182 using Minimum Quantity Lubrication with Different Nozzle Positions," Int. J. Precis. Eng. Manuf., Vol. 15, No. 3, pp. 557-565, 2014.

5. Klocke, F. and Eisenblätter, G., "Dry Cutting," CIRP AnnalsManufacturing Technology, Vol. 46, No. 2, pp. 519-526, 1997.

6. Nguyen, T. K., Do, I., and Kwon, P., "A Tribological Study of 
Vegetable Oil Enhanced by Nano-Platelets and Implication in MQL Machining,” Int. J. Precis. Eng. Manuf., Vol. 13, No. 7, pp. 10771083, 2012.

7. Bruni, C., Forcellese, A., Gabrielli, F., and Simoncini, M., "Effect of the Lubrication-Cooling Technique, Insert Technology and Machine Bed Material on the Workpart Surface Finish and Tool Wear in Finish Turning of AISI 420B," International Journal of Machine Tools and Manufacture, Vol. 46, No. 12, pp. 1547-1554, 2006.

8. Khan, M. and Dhar, N., "Performance Evaluation of Minimum Quantity Lubrication by Vegetable Oil in Terms of Cutting Force, Cutting Zone Temperature, Tool Wear, Job Dimension and Surface Finish in Turning AISI-1060 Steel," Journal of Zhejiang University SCIENCE A, Vol. 7, No. 11, pp. 1790-1799, 2006.

9. Dhar, N., Islam, M., Islam, S., and Mithu, M., "The Influence of Minimum Quantity of Lubrication (MQL) on Cutting Temperature, Chip and Dimensional Accuracy in Turning AISI-1040 Steel," Journal of Materials Processing Technology, Vol. 171, No. 1, pp. 9399, 2006.

10. Dhar, N., Kamruzzaman, M., and Ahmed, M., "Effect of Minimum Quantity Lubrication (MQL) on Tool Wear and Surface Roughness in Turning AISI-4340 Steel," Journal of Materials Processing Technology, Vol. 172, No. 2, pp. 299-304, 2006.

11. Sreejith, P., "Machining of 6061 Aluminium Alloy with MQL, Dry and Flooded Lubricant Conditions," Materials Letters, Vol. 62, No. 2, pp. 276-278, 2008.

12. Frățilă, D. and Caizar, C., "Investigation of the Influence of Process Parameters and Cooling Method on the Surface Quality of AISI1045 during Turning," Materials and Manufacturing Processes, Vol. 27, No. 10, pp. 1123-1128, 2012.

13. Gaitonde, V., Karnik, S., and Davim, J. P., "Optimal MQL and Cutting Conditions Determination for Desired Surface Roughness in Turning of Brass using Genetic Algorithms," Machining Science and Technology, Vol. 16, No. 2, pp. 304-320, 2012.

14. Liu, Z., Xu, J., Han, S., and Chen, M., "A Coupling Method of Response Surfaces (CRSM) for Cutting Parameters Optimization in Machining Titanium Alloy under Minimum Quantity Lubrication (MQL) Condition,” Int. J. Precis. Eng. Manuf., Vol. 14, No. 5, pp. 693-702, 2013.

15. Thakur, D. G., Ramamoorthy, B., and Vijayaraghavan, L., "Effect of Cutting Parameters on the Degree of Work Hardening and Tool Life during High-Speed Machining of Inconel 718," International Journal of Advanced Manufacturing Technology, Vol. 59, No. 5-8, pp. 483489, 2012.

16. Arunachalam, R., Mannan, M., and Spowage, A., "Surface Integrity When Machining Age Hardened Inconel 718 with Coated Carbide Cutting Tools," International Journal of Machine Tools and Manufacture, Vol. 44, No. 14, pp. 1481-1491, 2004.

17. Leppert, T., "Surface Layer Properties of AISI 3161 Steel When Turning under Dry and with Minimum Quantity Lubrication
Conditions," Proc. of the Institution of Mechanical Engineers, Part B: Journal of Engineering Manufacture, Vol. 226, No. 4, pp. 617631, 2012.

18. Krishnaiah, K. and Shahabudeen, P., "Applied Design of Experiments and Taguchi Methods,” PHI Learning Private Limited, 2012.

19. Senthilkumaar, J., Selvarani, P., and Arunachalam, R., "Selection of Machining Parameters based on the Analysis of Surface Roughness and Flank Wear in Finish Turning and Facing of Inconel 718 using Taguchi Technique," Emirates Journal for Engineering Research, Vol. 15, No. 2, pp. 7-14, 2010.

20. Dureja, J., Singh, R., and Bhatti, M. S., "Optimizing Flank Wear and Surface Roughness during Hard Turning of AISI D3 Steel by Taguchi and RSM Methods," Production \& Manufacturing Research, Vol. 2, No. 1, pp. 767-783, 2014. 